\title{
(Re)definición de los roles de género en la cultura popular. El caso de The Hunger Games
}

\author{
María Isabel Menéndez Menéndez \\ Universidad de Burgos. Área de Comunicación Audiovisual y Publicidad \\ mimenendez@ubu.es
}

\section{Marta Fernández Morales}

Universitat de les Illes Balears. Área de Filología Inglesa

marta.fernandez@uib.es

\section{Resumen}

La cultura popular asiste hoy a la (re)significación de las posiciones de héroe y de heroína mediante papeles emergentes que, en ocasiones, subvierten los roles de género. Este trabajo analiza dicha cuestión a partir de las adaptaciones fílmicas de la trilogía The Hunger Games, de Suzanne Collins. El interés del producto radica en su éxito de taquilla y en la originalidad de una propuesta dirigida a público adolescente que comparte pocas cosas con sus productos coetáneos, tanto por su discurso — más político-, como por la puesta en escena, que usa perfiles protagónicos inéditos. Se realiza aquí un estudio de representación descriptivo complementado con un análisis valorativo a partir de las contribuciones de la perspectiva de género como aporte epistemológico. Las conclusiones permiten sostener que The Hunger Games propone un nuevo perfil heroico que subvierte tanto el patrón hegemónico mediático como el orden patriarcal de las narrativas mainstream.

Palabras clave: antropología social; héroes y heroínas en el cine; subversión.

Abstract. (Re)definition of Gender Roles in Popular Culture: The Case of The Hunger Games

Popular culture today is witnessing the (re)signification of hero/ine positions through the appearance of emergent roles that occasionally subvert traditional gender roles. This paper analyzes this issue in the film adaptations of Suzanne Collins' trilogy The Hunger Games. The interest in this trilogy is rooted in its box office success and originality as a popular culture proposal for teenagers with few things in common with its coetaneous products, both because of its much more political discourse and due to its mise en scène, which includes the unprecedented profiles of its main actors. Our text provides a descriptive study of representation alongside an evaluative analysis based on the gender perspective as an epistemological approach. Our conclusions allow us to affirm that The Hunger Games proposes a new heroic profile that subverts both the hegemonic pattern found in media and the patriarchal order of mainstream narratives.

Keywords: social anthropology; film heroes and heroines; subversion. 


\section{Sumario}

1. Introducción 4. El cine de masas y las mujeres fálicas

2. The Hunger Games o el hambre como metáfora

3. Cuestiones epistemológicas: la categoría género y los perfiles heroicos en la cultura popular
5. The Hunger Games y la (re)definición del perfil heroico

6. Conclusiones

Referencias bibliográficas

Filmografía

\section{Introducción ${ }^{1}$}

La posmodernidad en la cultura de masas está experimentando procesos de (re) significación y (re)interpretación de los roles de héroe y heroína. Aunque todavía no sean mayoritarios, en algunos productos, la cultura popular abandona la representación hegemónica del héroe — generalmente, un varón hiperviril o macho alfa - para dejar espacio a nuevos perfiles protagonistas que, en ocasiones, subvierten los roles de género. Partiendo de esa realidad, el presente texto ofrecerá un estudio de caso mediante el análisis desde la perspectiva de género del nuevo perfil heroico que construye la cultura popular. Se realizará a través de las adaptaciones cinematográficas de las novelas disponibles hasta la fecha de la trilogía The Hunger Games, de Suzanne Collins': The Hunger Games (Gary Ross, 2012) y The Hunger Games: Catching Fire (Francis Lawrence, 2013), distribuidas ambas por Lionsgate Entertainment, propietaria de los derechos mundiales de distribución. La propia Collins adaptó la novela al cine, con la ayuda del guionista Billy Ray.

La elección de esta obra se justifica por varias razones: en primer lugar y más importante, por la originalidad desde el punto de vista de género, ya que su subversión de estereotipos es muy poco habitual en la cultura popular y, más especialmente, en los productos audiovisuales o literarios dirigidos a público adolescente. En segundo lugar, por lo inédito de mensajes políticos como los de Collins en las obras dirigidas a jóvenes y, en general, en la narrativa audiovisual posterior al $11-S^{3}$. Por otra parte, por su éxito incontestable

1. El presente trabajo se ha desarrollado en el marco del proyecto Violencia de género y cultura popular: Representación y recepción, cofinanciado por el Ministerio de Sanidad, Servicios Sociales e Igualdad del Gobierno de España y el Fondo Social Europeo (referencia 115/12).

2. The Hunger Games, publicado en 2008 en Estados Unidos, fue el primer volumen de una trilogía que se completó con Catching Fire (2009) y Mockingjay (2010). En 2012, fue llevada a la gran pantalla la primera de las novelas, con el mismo título y bajo la dirección de Gary Ross. La segunda parte, The Hunger Games: Catching Fire, se estrenaba en noviembre de 2013, dirigida por Francis Lawrence. Se prevé que dos nuevos filmes completen la saga cinematográfica en 2014 y 2015.

3. El grupo de investigación "Representación, ideología y recepción en la cultura audiovisual", liderado por una de las autoras de este artículo y al cual pertenecen ambas, ha publicado diversos trabajos sobre los productos audiovisuales creados tras los atentados de 2001 en Estados Unidos. Su trabajo más reciente es el volumen La década del miedo (Peter Lang, 2013). Más información en www.uib.cat/recerca/estructures/grups/grup/RIRCA/ y en el blog http://rirca.es. 
de taquilla ${ }^{4}$, lo que la hace digna de interés por su enorme resonancia, pero también porque se trata de un indicador - la recaudación- que está empezando a ser analizado desde una nueva óptica. $\mathrm{Al}$ respecto, el uso del test de Bechdel $^{5}$ ha demostrado que las películas con mujeres gozan generalmente de presupuestos sustancialmente menores, pero, contrariamente a la creencia en Hollywood sobre los peores resultados de taquilla, demuestran un mejor retorno de la inversión. En cuarto lugar, porque, ambientada en un mundo fantástico, comparte muchos elementos del mundo en que vivimos y, finalmente, porque, desde hace dos décadas, la denominada cultura popular ha abandonado su papel marginal en la literatura científica y ha pasado a formar parte del foco sociológico.

Tal y como explica Luengo, se trata de una ruptura con parámetros puramente empíricos para entrar en el territorio de la creación de significados, impulsando un «enfoque sociológico fuera de la tradición del funcionalismo", en el que la investigación se enfrenta, más allá de los hechos, a "prácticas» o acciones con significado (2006: 103). En este sentido, y superando el concepto de simple entretenimiento, The Hunger Games trata temas actuales y complejos, como la violencia, el totalitarismo o el papel de la tecnología en las sociedades contemporáneas.

La metodología del artículo se apoyará en un análisis de representación descriptivo complementado con un estudio valorativo a partir de la perspectiva de género como aporte epistemológico. Se partirá de la hipótesis de que la distopía The Hunger Games dibuja un nuevo rol heroico que, en esta ocasión, es encarnado por adolescentes y que subvierte tanto el patrón hegemónico mediático, como el orden patriarcal de los productos culturales mainstream. Respecto a la primera de las justificaciones de este trabajo, abordar las nuevas masculinidades y feminidades en la cultura popular es un reto al que se presta esta obra. Para los intereses académicos del presente texto, The Hunger Games es un relato que ofrece una (re)definición especialmente interesante de la feminidad normativa y que, a su vez, implica un nuevo acercamiento a los personajes masculinos.

4. La primera película recaudó más de 700 millones de dólares a nivel mundial y se convirtió en la cuarta más taquillera en la historia de los Estados Unidos. El estreno de la segunda parte en Norteamérica fue el mejor del mes de noviembre de todos los tiempos, con una recaudación en torno a los 172 millones de dólares. Con esta cifra, superó a la que hasta entonces ostentaba el récord de mejor película de estreno en ese mes: The Twilight Saga: New Moon (Chris Weitz, 2009). Además, hay que destacar que ha sido reconocida con diversos premios, como los galardones a mejor película, mejor actor (Josh Hutcherson) y mejor actriz (Jennifer Lawrence) en los MTV Movie Awards 2014. Asimismo, se ha creado un videojuego, The Hunger Games Adventures, lanzado a través de Facebook.

5. El test de Bechdel es un sistema de medición de sexismo, idea de la dibujante Alison Bechdel, que lo creó en una viñeta incluida en el cómic The Rule («Dykes to Watch Out For») en 1985. Usando este test, un estudio realizado por el periodista Walt Hickey y el equipo de FiveThirtyEight analizó 1.615 películas estrenadas desde 1990 hasta 2013 para examinar la relación entre la importancia de las mujeres en los filmes respecto a su presupuesto y a sus beneficios brutos. Los resultados principales obtenidos se sintetizan en que las películas con mujeres son más baratas y recogen mejores beneficios. Resultados disponibles en: http:// bechdeltest.com/. 
Aunque en este texto, y por razones de espacio, únicamente se reflexionará sobre el protagonismo de las jóvenes, hay que destacar que en The Hunger Games, subvirtiendo lo común en la filmografía mainstream, son los varones quienes constituyen el apoyo del personaje femenino, para quien se reserva el rol central y, por consiguiente, la construcción heroica. En efecto, la protagonista principal, Katniss Everdeen (interpretada por Jennifer Lawrence, cuya figura pública también ha abierto interesantes debates sobre las mujeres en Hollywood) ${ }^{6}$, encarna un rol de autonomía y poder sin doblegarse a una construcción estereotípica masculina, de forma que logra redefinir el perfil femenino que la cultura popular había reservado tradicionalmente para las mujeres. Como réplica, los personajes masculinos que la acompañan en su viaje (Peeta Mellark, interpretado por Josh Hutcherson, y Gale Hawthorne, a cargo de Liam Hemsworth) adoptan roles que tradicionalmente no han ocupado los varones, especialmente en relatos épicos ${ }^{7}$.

\section{The Hunger Games o el hambre como metáfora}

La obra de Suzanne Collins y su adaptación cinematográfica es, en esencia, un reproche a la sociedad del entretenimiento que combina feminismo y mensaje político accesible a las masas y, muy especialmente, a las personas jóvenes. Así, por ejemplo, y en relación con la profundidad del sentido crítico del relato, Peter Suderman escribió en The Washington Times: «[...] tal vez es una historia liberal, por la desigualdad y la división de clases. Tal vez es una épica libertaria de los males del gobierno autoritario. Tal vez es una revisión feminista de la ciencia-ficción de las películas de acción. Tal vez sea una sátira sangrienta de la telerrealidad", pero, añade, se limita a proponer estas teorías sin llegar a conclusiones (Suderman, 2012). Con todo, y aunque su público destinatario (adolescentes) y su cualidad de producto mainstream limitan el tono y la profundidad, subyace a los textos, tanto literarios como fílmicos, una crítica poco frecuente sobre la explotación de los individuos y sobre el uso y la manipulación de los medios de comunicación de masas.

El argumento se sitúa en un lugar llamado Panem que está dividido en distritos, siendo el Capitolio el que se reserva el poder y el lujo, mientras que el resto de territorios, empobrecidos y sometidos, son obligados a facilitar la materia prima para que el Capitolio perpetúe su estatus privilegiado. Como castigo a un levantamiento cuyo 75 aniversario se conmemora en los juegos de Catching Fire, y como táctica de intimidación para rememorar la victoria del Capitolio, cada año dos adolescentes de cada zona son enviados a un juego

6. La actriz Jennifer Lawrence ha sido criticada, dentro y fuera de la película, por su supuesto sobrepeso. Así, en la presentación de la primera entrega, críticas en periódicos como The New York Times o en The Hollywood Reporter cuestionaban el cuerpo de Lawrence por no representar a alguien que había soportado la hambruna. La ausencia de las mismas críticas respecto al resto de personajes permite asegurar que se trataba de afirmaciones sexistas.

7. Para profundizar en los personajes masculinos de The Hunger Games, puede consultarse Menéndez (2014). 
televisado en directo en el que deben luchar a muerte entre sí. Estos jóvenes y estas jóvenes se eligen mediante un sorteo que no es igualitario, ya que las familias más pobres pueden adquirir raciones de alimentos (teselas) a cambio de que el nombre de alguien entre más veces en la urna. En el juego hay patrocinadores dispuestos a ayudar a quienes deciden poner bajo su protección, mientras un grupo de técnicos monitorea el juego, añadiendo trampas para favorecer a alguien o para aumentar la tensión, revelando al mismo tiempo la manipulación del propio aparato, muy visible en la segunda de las películas a través del personaje de Plutarch Heavensbee, interpretado por el recientemente fallecido Philip Seymour Hoffman.

Panem es una sociedad basada en la fuerza bruta, el hambre, la «magia» tecnológica y la vigilancia constante (Pollitt, 2012). El producto final muestra la matanza adolescente bajo la mirada de unos controladores que pueden verlo todo ( $\mathrm{y}$ favorecer a quienes quieran); enseña las alianzas que permiten derrotar a adversarios (al estilo reality show) y pone en evidencia un mundo que se complace en la obscenidad de la muerte y su contemplación. Destinada a un público juvenil, las críticas a la violencia han sido numerosas, a pesar de que en los filmes se usa con mesura, apartándose en este sentido de la descripción de la novela original, donde la violencia es más cruda ${ }^{8}$.

The Hunger Games podría haberse denominado The Horror Games, pero parece que Collins ha elegido el hambre como algo más que un título. El hambre es una metáfora de todo lo que acontece, porque la trilogía es un relato de ciencia-ficción con alegoría política (aunque puede quedarse corta para el público adulto, como ya apuntábamos). Es el símbolo de un pueblo sometido y controlado, al que se niega tanto el alimento como la posibilidad de buscarlo por sí mismo. Forma también parte de la expresión clásica que compone el nombre de Panem (pan y circo), en una sociedad que parece disfrutar de la teatralización del horror. Es, por último, el símbolo del héroe trágico que, en el caso de The Hunger Games, se concreta en una pareja de protagonistas unidos por el pan desde la génesis de su relación. En efecto, Katniss tuvo contacto con Peeta en un momento anterior a "la cosecha» (el momento de elección de adolescentes para los juegos) cuando, hambrienta y desesperada, recibió el pan desechado que Peeta — el hijo del panadero— le hizo llegar a escondidas de su familia.

La lucha que contemplamos en The Hunger Games no es solo la batalla por sobrevivir en los juegos, sino la de todo un pueblo ante el totalitarismo. Como en un relato mitológico, una sociedad inocente debe asumir un castigo

8. En los Estados Unidos, donde las matanzas en institutos forman parte de su historia reciente, el filme que abría la saga cinematográfica despertó polémica por su visión nada edulcorada de la violencia entre jóvenes, por su sátira de la sociedad posindustrial en decadencia y por su carga de crueldad. En el Reino Unido, se solicitó al British Board of Film Classifications que fuera considerada no apta para menores de 15 años, partiendo de la idea de que podía ser traumático para las jóvenes y los jóvenes ver cómo se mataban entre sí otros y otras adolescentes. Para lograr la clasificación 12A, Lionsgate tuvo que sustituir algunos segundos de la película para eliminar imágenes de sangre en cuerpos y armas. 
y pagar con la vida de sus hijos e hijas. A los tributos, no obstante, se les ofrece la posibilidad (remota) de sobrevivir si son lo bastante fuertes y astutos. Sin embargo, The Hunger Games demuestra que ni siquiera existe igualdad entre quienes pelean por su vida en la arena: la lucha de clases, los prejuicios, el poder establecido y la capacidad de persuasión se revelan como cuestiones estratégicas.

Destinada al mismo público que su casi contemporánea Twilight (Stephenie Meyer, 2005), esa es la única característica que comparten ambas sagas, junto al éxito editorial y cinematográfico ${ }^{9}$. La obra de Collins provee temas de reflexión más adultos: los movimientos sociales, la globalización neoliberal, el poder gubernamental y mediático, las hambrunas de medio planeta frente a la riqueza de unos pocos, la cultura de los videojuegos y del horror como espectáculo, la infancia y los conflictos bélicos, la manipulación de las audiencias, el auge de la telebasura y el morbo... Todos estos asuntos aparecen en The Hunger Games, que, además, apenas muestra un interés difuso por las relaciones sentimentales de los personajes. Es un producto mainstream que, sin embargo, intenta no serlo. Y lo hace mediante la elección de un argumento político y también con una mirada más indie que, en el caso de las versiones para la gran pantalla, se aprecia particularmente en el tratamiento visual y en la banda sonora.

Aunque la muerte de adolescentes es intrínseca al relato, los personajes no han de tomar decisiones que comprometan su integridad, pues otras personas las han tomado ya por ellos. Deben matar a sus iguales en un juego nefasto del que no pueden escapar y que no han contribuido a diseñar. La novedad en el relato de Collins es que la audiencia de este reality show letal tiene un papel activo: el público ya no es inocente. Extradiegéticamente, se construye una crítica al imperio de la imagen en los medios de masas (y cómo la televisión crea realidades en nombre de la audiencia, situación que incomoda especialmente a Katniss), pero también la degradación moral de la telebasura y su público. Por otra parte, veremos que la elección de una mujer como protagonista no cae en el estereotipo de mujer fálica, es decir, personajes femeninos asimilados a los varones, lo que les colocaría en el poder solo aparentemente, esto es, sin capacidad para subvertir el modelo canónico (Bernárdez, 2012). De la misma forma, no se trata de un personaje que responda a las características habituales de las protagonistas prototípicas del cine, tal y como se expondrá en los epígrafes siguientes.

\section{Cuestiones epistemológicas: la categoría género y los perfiles heroicos en la cultura popular}

La categoría género, construida académicamente a mediados de la década de 1970 tras la publicación de un artículo ya clásico de Gayle Rubin — «The Traffic in Women» (1975) —, ha obligado a repensar las perspectivas inter-

9. La trilogía de Collins, solo en 2012, vendió 27,7 millones de copias a nivel mundial (Vales, 2013: 83). 
pretativas de las disciplinas sociales. Esta nueva etiqueta permite referirse a los procesos de «diferenciación, dominación y subordinación entre los hombres y las mujeres» (Lamas, 2013: 11). Las coordenadas del concepto fueron establecidas más tarde en un artículo de la historiadora Joan W. Scott: «Gender: A Useful Category of Historical Analysis» (1986), un texto clave que revisaba los usos de la categoría, ordenando y clarificando el debate que se había abierto en las ciencias sociales, al establecer rotundamente la distinción entre construcción social y biología (Lamas, 2013: 17). El artículo de Scott proponía dos ideas principales: el género es un elemento constitutivo de las relaciones sociales basadas en las diferencias entre los sexos, y el género es una forma primaria de relaciones significantes de poder.

$\mathrm{Si}$, en un principio, el concepto fue enormemente útil para disciplinas como la antropología, sería en la teoría política y la filosofía donde más desarrollo iba a experimentar (Lamas, 2013: 18). Así, cuestionar los códigos heredados y analizar la construcción de los sujetos se convertirá en una tarea política e intelectual urgente, un ejercicio que, como señala la antropóloga mexicana Marta Lamas, necesita del fortalecimiento antisexista y antihomófobo en el contrato social. De ahí la labor sistemática de crítica cultural y (de)construcción de los discursos, incluyendo los mediáticos, que ha nutrido el interés académico en las últimas décadas. Así, en el proceso de construcción del género, las personas adultas son modelos que ejercen influencia en la interacción cotidiana de niñas y niños, por lo que está asumido que «la observación de conductas, tanto en modelos vivos como simbólicos (cine, televisión o libros), facilita el aprendizaje de los diversos patrones de conducta diferenciados por razón de género» (Rodríguez y Peña, 2005: 168).

En el contexto audiovisual, sería otro artículo fundamental, «Visual Pleasure and Narrative Cinema» (1975), de Laura Mulvey, el que abriría la crítica al sistema audiovisual cinematográfico. La autora, con un enfoque psicoanalítico, descubrió que la diferencia sexual opera de tal forma que domina no solo las imágenes, sino también la forma de mirarlas. Para Mulvey, el inconsciente de dominación patriarcal establece un sistema jerárquico desde el punto de vista de género que se incardina en el propio lenguaje cinematográfico y que afecta tanto a los modos de ver como al propio placer de mirar. La autora, que estudió el periodo clásico de Hollywood, considera que, en el cine, coexisten tres tipos de miradas: la de la cámara (que decide aquello que verá el público), la de los personajes y, por último, la del espectador o la espectadora. Tanto la primera como la última están en función de las miradas internas de los personajes. En esta estructura, se producen dos tipos de placer visual: el instinto escopofílico y la identificación narcisista.

La obra de esta experta se ha convertido en un referente imprescindible por su explicación de cómo el cine reproduce la jerarquía binaria activo/pasivo y sujeto/objeto que existe en la sociedad. El varón, para Mulvey, es el portador de la mirada (sujeto activo), mientras que la mujer es solo receptora (sujeto pasivo). Ello explica que los personajes femeninos sean un objeto erótico supeditado al deseo masculino. El texto, aunque discutido más tarde por cuestiones 
como la heteronormatividad de su enfoque o el uso del psicoanálisis, define la male gaze ('mirada masculina'), que se ha convertido en referencia indispensable para los estudios fílmicos feministas, influenciando a autoras fundamentales para este campo de estudio como Annette Kuhn, Ann Kaplan, Teresa de Lauretis o la española Pilar Aguilar, cuyo trabajo se referencia más abajo.

Es un hecho que la organización social en la que vivimos provee espacios, tareas y roles distintos y jerarquizados a hombres y mujeres; diferencias que se aprenden en el proceso de socialización: «La mujer, como el hombre, no son un punto de partida, sino un resultado» (Izquierdo, 2013: 95). Es decir, masculinidad y feminidad, ser hombre o ser mujer, constituyen construcciones históricas, económicas, sociales y psíquicas. Sin embargo, recuerda la socióloga María Jesús Izquierdo, no se trata de una relación de complementariedad, sino de desigualdad: hombres y mujeres no tienen el mismo valor, como tampoco se consideran de la misma forma las actividades que desarrollan. Esta desigualdad afecta, finalmente, a las relaciones de género, pues tanto ellos como ellas «terminan comportándose como se espera en relación con su género, con lo cual se reproducen las relaciones desiguales» (Botía-Morillas, 2013: 447).

Desde el punto de vista del rol, la masculinidad se identifica con lo que De Moya llama «noción totalitaria» (2003: 186), esto es, una representación basada sobre todo en la fuerza y cuyo correlato cinematográfico son los héroes hiperviriles que deben proteger o liberar al mundo entero (Lohmüller, 2011: 262). Es lo que se ha dado en llamar macho alfa o masculinidad tradicional, caracterizada por «la fuerza, el coraje, la astucia, la ambición, el poder» (Zurian, 2011: 291). En cuanto a la feminidad y a las mujeres, de acuerdo con Pilar Aguilar (2004: 9), en la representación y el papel de éstas en las ficciones audiovisuales se dan ciertas constantes: en primer lugar, la ausencia como sujeto simbólico, o lo que es lo mismo, la perspectiva androcéntrica. Las mujeres son objeto de visión, casi nunca sujeto. Por otro lado, las mujeres son «episódicas», en el sentido de que su acción es secundaria, parcial o un incidente de la trama. Son marginales respecto al relato (siendo, por ejemplo, el trofeo del guerrero o su descanso). En tercera instancia, el cuerpo de las mujeres en el cine es un ente fragmentado, cosificado, sobre el que la cámara se recrea en planos estáticos que, de contemplativos, en ocasiones llegan a ser agresivos. Relacionado con ello, encontraríamos lo que Aguilar da en llamar «sexualidad amputada», en el sentido de que erotismo y sexualidad aparecen mayoritariamente en función del sujeto masculino: genitalidad viril frente a unos personajes femeninos que parecen no tener sexualidad propia. En quinto lugar, la asimilación femenina a los varones es tal que, en muchas ocasiones, la protagonista es un sujeto que imita los modos y las maneras masculinos, por ejemplo: mediante la asunción de violencia o brutalidad. Otra característica más de las mujeres de la pantalla tiene que ver con la ausencia de criterios ideológicos o políticos propios y, por otro lado, los personajes femeninos, con frecuencia, aparecen como seres caprichosos, incongruentes, torpes o inútiles. Los hombres que están a su lado no tienen más remedio, por consiguiente, que dotarse de paciencia para soportarlas o, incluso, para asumir un riesgo añadido que consiste en la mera presencia del personaje. 
No obstante, esa hegemónica representación que acabamos de describir asiste a una subversión mediante la "fantasía heroica feminista» (Pitarch, 2008: 40). Algunas obras son capaces de subvertir los estereotipos heroicos fílmicos para conceder un papel preeminente a mujeres, trasladar la idea de empoderamiento femenino y conceder a los varones una posición subordinada y/o secundaria (Chicharro, 2013: 16). Este es el caso de las dos entregas vistas hasta ahora de la saga The Hunger Games. Solo una ínfima parte de la narrativa audiovisual reserva espacio para mujeres autónomas, inteligentes o arriesgadas sin convertirlas en varones, de ahí que sea importante poner en valor las subversiones que se observan en ficciones como las que adaptan el trabajo de Collins.

\section{El cine de masas y las mujeres fálicas}

La crítica fílmica feminista, como hemos visto en el epígrafe anterior, ha señalado que el protagonismo femenino en el cine, especialmente en narrativas épicas o de aventuras, ha sido inexistente, solo superado por la aparición reciente de la mujer fálica. Este concepto, hijo del psicoanálisis, es un simbolismo para definir a una mujer con rasgos o actitudes varoniles, con personalidad autoritaria, deseos de poder, de poseer o de venganza. En esta etiqueta se incluiría a mujeres con varios amores o amantes, pero también guerreras o soldados, entre otras. La mujer fálica, la que está dotada simbólicamente de poder y/o de autoridad, se corresponde, además, con diversos perfiles, desde la mujer seductora hasta la protectora o la madre castradora (Green, 1968: 23). Desde un punto de vista psicoanalítico, no tiene ninguna relación con la opción sexual, sino que se trata de la representación psíquica y social del órgano masculino y no del órgano mismo (es decir, falo no es lo mismo que pene). Por ello, una mujer que actúa de forma masculina - más bien con lo que habitualmente se considera como tal-, con características dominantes y perfil varonil en las opciones que utiliza para encarar los problemas, sería una mujer fálica. La cuestión sugiere, contra lo que propone la cultura patriarcal, que es posible intercambiar los roles de género. Ello quiere decir que, independientemente del sexo, se puede adoptar un rol masculino o femenino, tal y como defienden teorías feministas posmodernas (Mayayo, 2002: 34).

Lo antedicho sugiere algunas cuestiones básicas. La primera de ellas, que la propia definición de mujer fálica puede situar el análisis en el mismo esencialismo que los estudios de género han criticado desde hace décadas. Para evitar caer en el mismo problema que se intenta evitar, es imprescindible explicar que los roles masculino y femenino son construcciones culturales y que, asumirlos como punto de partida, no implica aceptar ni su carácter inmutable ni su naturalización. Situarse en la perspectiva de género consiste en referirse a los modos en que las sociedades «comprenden, debaten, organizan y practican las diferencias y similitudes relacionadas con lo femenino y lo masculino" (Téllez y Verdú, 2011: 88).

Así pues, entendemos la representación de la masculinidad, en primer lugar, como la autoridad simbólica de lo masculino frente a lo femenino: 
«La aceptación de lo masculino como norma [...] se alimenta de la pervivencia de un universo simbólico en el que lo masculino, todavía vinculado a la autoridad, la razón y el poder, muy difícilmente llega a cuestionarse» (Téllez y Verdú, 2011: 82). Por otro lado, la masculinidad como constructo —al igual que la feminidad - es múltiple y varía según el espacio, el tiempo o la cultura, aunque responde a algunas constantes entre las que destacan la capacidad de luchar e infligir dolor, el deseo de aventura, el control sobre cosas y personas, la competitividad y la agresividad y la ausencia de sentimientos. Esta masculinidad tradicional es la que ha servido para perpetuar el patriarcado a lo largo de la historia, un sistema en el que los privilegios masculinos se glorifican, puesto que refuerza el poder de los varones $\mathrm{y}$, más específicamente, el poder de éstos sobre las mujeres. Finalmente, definir la masculinidad consistiría en precisar, más allá del esencialismo y situándonos en un paradigma interpretativo, "lo-que-los-hombres-empíricamente-son, es tener en mente el uso por el cual llamamos a algunas mujeres masculinas y a algunos hombres femeninos, o a algunas acciones o actitudes masculinas o femeninas» (Téllez y Verdú, 2011: 92).

La aparición en el cine de mujeres fálicas, a partir de la década de 1980, sería un resultado - aunque no deseado- de las reclamaciones feministas de la segunda ola (Bernárdez, 2012: 96). Tras una lucha que exigía la visibilización de las mujeres y el reparto de espacios y, sobre todo, de poder, la creación de personajes que respondían a un modelo alternativo pudo entenderse como una conquista feminista. Estas protagonistas utilizaban las armas masculinas (poder, violencia, control) y no las femeninas (seducción, manipulación emocional, instrumentalización de la supuesta debilidad), pero, además, aparecieron con un cuerpo hipersexualizado - que difiere radicalmente del musculado cuerpo varonil - y que, finalmente, no las separaba de lo esperado para la feminidad ${ }^{10}$.

La cuestión no resuelta en la crítica feminista respecto al uso de la violencia en las mujeres junto a esta polarización entre cuerpo hipersexualizado y uso de actitudes varoniles es la que hace difícil entender estos personajes como realmente empoderados, aunque ambas lecturas sean posibles. De acuerdo con Bernárdez (2012: 93), estas protagonistas ponen en cuestión el orden social, sobre todo en lo tocante al uso de la violencia, pues, para el patriarcado, es inaceptable el binomio mujer y violencia, pero plantean retos al feminismo sobre si son o no figuras positivas que vienen a corregir un imaginario básicamente androcéntrico. Esta dualidad podría responder — sostiene Bernárdez siguiendo a Faludi y a su texto ya clásico de 1991- a la necesidad de castigar aquellas representaciones que no cumplían con el mandato de género, en una época, los años noventa, de fuerte reacción conservadora. En este sentido, la representación de las mujeres guerreras o violentas podría ser, no un empoderamiento, sino una domesticación o neutralización (Bernárdez, 2012: 100).

10. Ejemplos de estos personajes fálicos serían, por ejemplo, el encarnado por Angelina Jolie en Lara Croft. Tomb Raider (Simon West, 2001) y su secuela, o el interpretado por Uma Thurman en Kill Bill I y II (Quentin Tarantino, 2003 y 2004). 
Esta idea de la creación de mujeres sancionadas simbólica y públicamente como mecanismo de control volvería a ser defendida por Faludi en su obra de 2007.

De acuerdo con lo anterior, el personaje de Katniss Everdeen en The Hunger Games no responde a la etiqueta de mujer fálica, ya que, en primer lugar, su apariencia no está sexualizada. Por otra parte, la motivación de la acción, que en las mujeres fálicas del cine anterior casi siempre obedecía a un impulso masculino - visible o no-, en Everdeen no existe, pues ella es una joven que, debido a sus circunstancias familiares, debe hacerse cargo del sustento de su madre y su hermana. Es precisamente la necesidad de proteger a ese núcleo familiar lo que la hace presentarse voluntaria para sustituir a su hermana Prim, cuyo nombre había resultado elegido en el sorteo. Katniss se ofrece a reemplazarla, porque es consciente de la nula posibilidad de sobrevivir que tiene la pequeña de doce años, aunque asumiendo que ella tampoco tendrá muchas más opciones. En el mismo orden de cosas, y a pesar de su juventud, el personaje de Katniss ofrece con frecuencia una reflexión sobre lo que la sociedad espera de las mujeres. Para ella, es discutible que todas deban casarse y ser madres — y manifiesta su deseo de no seguir ese modelo—, y le parece un mandato insoportable la necesidad de obedecer al patrón estético normativo, muy importante en la narrativa de The Hunger Games, especialmente en lo relativo a la aparición en la pequeña pantalla.

\section{The Hunger Games y la (re)definición del perfil heroico}

La novedad de Katniss Everdeen, figura principal de la saga de Suzanne Collins, radica, como ya se ha dicho, en que no obedece al modelo fálico. La protagonista de The Hunger Games es una heroína trágica, porque no desea el destino que le toca vivir. Rechaza, como los héroes épicos, la responsabilidad de la tarea que le viene encima y, contra su voluntad, se convierte en una líder. Esto resulta especialmente evidente en el filme Catching Fire, donde se recoge la gira organizada para homenajear a los vencedores de los juegos y la reacción de los distritos a la presencia de la joven: Katniss no solo ofrece esperanza a la población del desgraciado Panem, sino que también es capaz de convertirse en todo un símbolo mítico que llega a amenazar al poder establecido, especialmente a partir de esta segunda entrega cinematográfica, cuando el personaje pierde la inocencia y asume un rol activo en la revolución. Katniss se enfrenta con valor y coraje a una aventura directamente emparentada con la muerte, sin acercarse nunca al retrato de superhéroe que domina la cultura de masas cuando se trata de salvar al mundo.

Cierto es que Everdeen es descrita según el modelo de amazona mediática definido por Mainon y Ursini (2008: 24-27): es una experta en el uso del arco y la flecha, habilidad que le permitirá sobrevivir, primero, en la vida ordinaria (al conseguir alimento) y, después, en la lucha a vida o muerte a la que se ve abocada. Pero esta caracterización no se realiza mediante la masculinización ni Katniss aparece hipersexualizada como la mayoría de guerreras cinematográficas. Lucha agresivamente porque no tiene alternativa (solo mata en legítima 
defensa); desarrolla su empatía de género (especialmente en su relación con la pequeña Rue del Distrito 11 en la primera de las entregas); utiliza un arma típica (el arco y las flechas); es independiente hasta el punto de que se encarga del sustento de toda su familia; procede de una civilización perdida y carece de interés en los hombres y en la construcción romántica como centralidad femenina (aunque se siente atraída por su amigo Gale Hawthorne, no se abandona a las posibilidades de esa relación). Aparece, en fin, como un sujeto autónomo que ha asumido responsabilidades muy superiores a las habituales para su edad y que no sucumbe al mito romántico ni a la feminidad normativa. No es una mujer travestida, ni tampoco masculinizada, a pesar de que no sigue la construcción tradicional de feminidad.

El personaje de Everdeen es un héroe político (Cardona, 2006: 59), porque encarna los ideales morales de la sociedad: posee valores físicos y sociales excepcionales, reconocidos por la colectividad, y la fortaleza es, junto a su moral, una de sus cualidades más destacadas. También es valiente, aunque no hasta el punto de apartarse de la condición humana. Su perfil trágico se manifiesta por la presencia constante del sufrimiento en su vida. Esto explica que, cuando sobrevive a los juegos en la primera entrega de la saga, se convierta en un modelo para todo el mundo y, más tarde, en símbolo de la rebelión ante la tiranía, personificada por el presidente Snow (interpretado por Donald Sutherland), que, en Catching Fire, se obsesiona con destruirla. Esta segunda película, estrenada en noviembre de 2013, es más dramática y comprometida socialmente que la anterior, tal y como sucede en las novelas. En ella, Katniss aparece con mayor profundidad emocional y política. El filme de Francis Lawrence, además, representa, para el personaje protagonista, el fin de la ingenuidad y de las decisiones que otras personas toman por ella: debe resolver por sí misma si quiere someterse al terror o, por el contrario, rebelarse ante él.

Como la mayoría de obras protagonizadas por mujeres, The Hunger Games no es ajena a la crítica respecto a su posible feminismo, lo cual despierta reflexiones encontradas. No obstante, hay cuestiones que arrojan luz sobre el asunto. Al protagonismo incontestable del personaje de Everdeen, hay que añadirle otros indicadores, como que, entre las doscientas películas con más éxito de taquilla en la historia del cine, nunca ha aparecido una protagonista femenina, lo que revela el carácter inédito de Katniss. Aunque es pronto para encontrar textos científicos, el tema sí ha despertado interés en las páginas periodísticas dedicadas a la crítica cinematográfica.

Así, por ejemplo, Manohla Dargis y A. O. Scott —quienes firman las críticas de cine más importantes en el diario The Washington Post- debatieron sobre el personaje en un reportaje publicado con ocasión del estreno de la primera película y en el que se preguntaban si Katniss Everdeen era un nuevo prototipo de mujer guerrera (Scott y Dargis, 2012). Dargis considera que Katniss viene a poner punto y final a la representación del héroe hegemónico que Lewis denominó American Adam, individuo ahistórico y sin familia, solo e independiente, capaz de enfrentarse a cualquier cosa con sus únicos recursos. Para Dargis, la protagonista de The Hunger Games se diferencia de la mayoría 
de protagonistas femeninas, reducidas casi siempre a papeles de madre, víctima o novia, y lo hace sin polarizarse en un perfil de masculinidad o feminidad, transitando entre ambas posibilidades, esto es, asumiendo ambos roles.

Por su parte, Scott considera que la confusión en las identidades de género no es algo nuevo, pues lo encontramos en el cine desde la misma Marlene Dietrich, pero sí es interesante fijarse en cómo las heroínas contemporáneas - entre ellas Katniss, pero también Lisbeth Salander en Millenium-absorben contradictorios códigos de género. En Everdeen, hay ecos del arquetipo heroico de la literatura del oeste americano, especialmente de Natty Bumppo, una persona socialmente marginal, alguien que defiende la sociedad frágil de la frontera sin llegar a ser parte de ella.

Según Scott, Everdeen soporta la carga de múltiples identidades simbólicas: es una atleta, una estrella de los medios de comunicación y una guerrera; pero también es una hermana, una hija, una amiga leal e, incluso, una novia potencial. Desde el punto de vista cinematográfico, encarna el perfil heroico del oeste, del héroe en acción y de la heroína romántica. Es Natty Bumppo, pero también la mítica Diana la cazadora, una síntesis entre Harry Potter y Bella Swan de la saga Twilight. La fuerza del personaje, argumenta Scott, se apoya precisamente en la capacidad de aunar todos esos significados en un personaje creíble, un personaje que nunca es pasivo ni débil y que permite realizar una identificación universal. Así, hoy se asumiría que las niñas quieran emular a Harry Potter o a los superhéroes de la pantalla, siempre sin socavar su propia feminidad, pero es impensable que los niños quieran jugar a ser princesas, de ahí el potencial de Everdeen desde el punto de vista de género.

No obstante, no se trata de un enfoque unánime. Kate Heartfield (2012), del periódico canadiense Ottawa Citizen, considera que únicamente se trata de una película de éxito protagonizada por un personaje femenino, mujer con características masculinas que nunca cuestiona los paradigmas patriarcales. En su opinión, Katniss no tiene ninguna ambición, ningún interés en la política más allá de una venganza personal, mientras que su acción está motivada por el amor a su familia. Todo ello explica que nunca sea una amenaza para el orden social, por lo que, según Heartfield, el poder femenino de The Hunger Games y las luchas feministas de 2012 están muy alejadas.

Sorprendentemente, en opinión de Heartfield, Katniss Everdeen se acerca mucho a Bella Swan, la creación de Stephenie Meyer para su popular saga vampírica ya mencionada. Respecto a esta cuestión, surgieron numerosas respuestas de lectores y lectoras que no compartían esta afirmación de Heartfield sobre un personaje muy diferente en las cuestiones afectivas y cuyo rechazo al amor de Gale y de su masculinidad hegemónica - especialmente en lo relacionado con la violencia - aparece con claridad según avanza la historia. La definición de Peeta como un «artista sensible» y, sobre todo, la lenta progresión de Katniss en las cuestiones amorosas, la harían estar muy alejada del personaje de Twilight, tal y como argumentaba una lectora - Athena Raypold, de la Grant MacEwan University en Edmonton, quien a la sazón estaba escribiendo su tesis sobre The Hunger Games- que sí consideraba que la obra sobre vampiros carecía de 
discurso feminista. Para Raypold, tampoco puede aceptarse que el personaje de Everdeen esté exento de ambiciones políticas, pero es necesario darle tiempo, pues, cuando llega por primera vez a los juegos con apenas 16 años, no puede hacer mucho más que sobrevivir. Con el paso del tiempo, sí se convierte en un personaje activo en la rebelión y comprometido con la causa de derrocar el régimen político del Capitolio, lo que vemos con claridad en la segunda entrega de la saga, tal y como hemos expuesto en el epígrafe precedente.

Es cierto que el discurso feminista puede ser superficial para mujeres adultas - no hay que olvidar que The Hunger Games es un producto destinado a público adolescente- o en comparación con algunas agendas pendientes sobre los derechos de las mujeres, pero el personaje de Katniss es una novedad como mujer capaz de alcanzar el éxito, (de)construyendo el género desde un rol que ni es feminidad normativa ni masculinidad hegemónica, negando que la forma de terminar con la discriminación de género pase por la eliminación de discursos opresivos.

\section{Conclusiones}

The Hunger Games propone una subversion de los roles de género muy poco frecuente en la cultura popular, especialmente en las producciones destinadas a público adolescente. Lo hace, en primer lugar, mediante la elección de un perfil de protagonista irrefutable que puede definirse como feminista: Katniss Everdeen es autónoma, se enfrenta a la tarea heroica con coraje y no pierde la dignidad en ningún momento. La historia no elige para ella un aspecto sexualizado ni tampoco asexual, es atractiva pero terrenal y, sobre todo, es inteligente y valiente, capaz de defenderse sola en los escenarios más hostiles. Contrariamente a lo común en las producciones mainstream, el personaje no cae en tentaciones románticas ni se construye como alteridad, desdibujada sin la presencia del varón. Katniss no necesita ser salvada por nadie y, de hecho, manifiesta con frecuencia su deseo de independencia, aunque sin llegar a deshumanizarse, puesto que el guión de las películas presenta a menudo sus dudas y sus miedos.

Con todo, The Hunger Games también presenta retos al análisis de género, básicamente porque, aunque lo invierte, no supera la dualidad entre masculino y femenino y deposita en la heroína una responsabilidad familiar que puede entenderse como típicamente femenina, ejemplo de la ética del cuidado (muy visible en su relación con su hermana pequeña Prim). No obstante, esta responsabilidad también podría leerse en clave subversiva, al asumir Katniss el rol tradicionalmente masculino de breadwinner (proveedora principal de la familia).

Por otra parte, y como lo suele hacer la cultura mainstream, la historia de The Hunger Games se instala en la heterosexualidad obligatoria, a pesar de que el escenario del relato es un mundo posapocalíptico donde muchos elementos superan definiciones normativas - como los patrones estéticos o los artilugios fantásticos-, lo que hubiera permitido introducir una evolución de la sexualidad canónica. Solo uno de los personajes importantes para Katniss —el estilista 
Cinna, interpretado en el cine por el cantante Lenny Kravitz- es definido como bisexual.

Hay que destacar, finalmente, que, junto a la crítica al poder totalitario y a la manipulación mediática y política que aparece con claridad en The Hunger Games, los roles de género que describe Collins son una novedad positiva en obras dedicadas fundamentalmente a público adolescente, una obra arriesgada y sorprendente en la cultura posterior al 11-S que construye un nuevo perfil heroico hasta ahora prácticamente inexistente en la cultura popular.

\section{Referencias bibliográficas}

Aguilar, Pilar (2004). ¿Somos las mujeres de cine?: Prácticas de análisis filmico. Oviedo: Instituto Asturiano de la Mujer.

Bechdel, Alison (1985). «Dykes to Watch Out For». The Rule, 22. $<$ http://dx.doi.org/10.2307/4024193>

BERnáRDEZ, Asunción (2012). «Modelos de mujeres fálicas del postfeminismo mediático: Una aproximación a Millenium, Avatar y Los juegos del hambre». Anàlisi, 47, 91-112.

Botía-Morillas, Carmen (2013). «Cómo diseñar una investigación para el análisis de las relaciones de género: Aportaciones metodológicas». Papers, 98 (3), 443-470.

Cardona, Patricia (2006). «Del héroe mítico, al mediático: Las categorías heroicas: héroe, tiempo y acción». Revista Universidad EAFIT, 42 (144), 51-68.

Chicharro, Mar (2013). «Representaciones de la mujer en la ficción postfeminista: Ally McBeal, Sex and the City y Desperate Housewives». Papers, 98 (1), 11-31.

Collins, Suzanne (2008). The Hunger Games. Nueva York: Scholastic Press.

- (2009). Catching Fire (The Second Book of 'The Hunger Games'). Nueva York: Scholastic Press.

- (2010). Mockingjay (The Final Book of 'The Hunger Games'). Nueva York: Scholastic Press.

Faludi, Susan (1991). Backlash: The Undeclared War Against American Women. Nueva York: Broadway Books. $<$ http://dx.doi.org/10.2307/4065531>

- (2007). The Terror Dream: Myth and Misogyny an Insecure America. Nueva York: Henry Holt \& Co.

<http://dx.doi.org/10.14431/aw.2009.06.25.2.99>

Green, André (1968). «Sur la mère phallique». Revue Française de Psychanalyse, 32 (1), 1-38.

Heartfield, Kate (2012). «The Hunger Games Is No Feminist Manifesto». Ottawa Citizen, 29 de marzo.

IzQuierdo, María Jesús (2013). «La construcción social del género». En: DíAz, Capitolina y Dema, Sandra (eds.). Sociología y género. Madrid: Tecnos, 87-112.

Lamas, Marta (2013) [1996]. «Introducción». En: Lamas, Marta (comp.). El género: La construcción cultural de la diferencia sexual. México D. F.: Miguel Ángel Porrúa y PUEG, 9-20.

LOHMÜLLER, Torben (2011). «El espectáculo de la identidad masculina y la mirada gay: Algunas observaciones acerca de Querelle de Fassbinder». En: Zurian, Francisco (ed.). Imágenes del Eros: Género, sexualidad, estética y cultura audiovisual. Madrid: Ocho y Medio, 260-276. 
Luengo, María (2006). «Fundamentos y carencias de los estudios culturales: Una revisión teórico-crítica del ámbito popular culture». REIS: Revista Española de Investigaciones Sociológicas, 115, 101-133. $<$ http://dx.doi.org/10.2307/40184768>

Mainon, Dominique y Ursini, James (2008). Amazonas: Guerreras en la pantalla. Madrid: Alberto Santos Editor.

Mayayo, Patricia (2002). Louise Bourgeois. Hondarribia: Nerea.

MenéndeZ, María Isabel (2014). «Héroes posmodernos en la ficción audiovisual: The Hunger Games y la masculinidad no hegemónica». En: Zurian, Francisco (ed.). Hombres Filmados. Representaciones audiovisuales de (nuevas) masculinidades. Madrid: Síntesis (en prensa).

Meyer, Stephenie (2005). Twilight. Nueva York: Paperback.

Moya, Antonio de (2003). "Versiones y subversiones de la masculinidad en la cultura dominicana». Perspectivas Psicológicas, 3-4 (4), 186-192.

Mulvey, Laura (1975). "Visual Pleasure and Narrative Cinema». Screen [en línea], 16 (3), 6-18. <http://dx.doi.org/10.1093/screen/16.3.6>.

Pitarch, Pau (2008). "Género y fantasía heroica». En: Clúa, Isabel (ed.). Género y cultura popular I. Barcelona: Ediciones UAB, 33-64.

Pollitt, Katha (2012). «The Hunger Games'Feral Feminism». The Nation, 23 de abril.

Rodríguez, M. a del Carmen y Peña, José Vicente (2005). "Identidad de género y contexto escolar: Una revisión de modelos». REIS: Revista Española de Investigaciones Sociológicas, 112, 165-194.

Rubin, Gayle (1975). «The Traffic in Women: Notes on the 'Political Economy' of Sex». En: Reiter, Rayna (comp.). Toward an Anthropology of Women. Nueva York: Monthy Review Press, 157-210.

Scott, A. O. y Dargis, Manohla (2012). "A Radical Female Hero From Dystopia». The New York Times, 4 de abril.

Sсотт, Joan (1986). «Gender: A Useful Category of Historical Analysis». American Historical Review [en línea], 91, 1053-1075. <http://dx.doi.org/10.2307/1864376>.

Suderman, Peter (2012). "The Hunger Games Offers a Feast for Sci-fi Fans». The Washington Times, 21 de marzo.

Téllez, Anastasia y Verdú, Ana Dolores (2011). «El significado de la masculinidad para el análisis social». Nuevas Tendencias en Antropología, 2, 80-103.

Vales, Cristina (2013). «El fuego de la revolución». Cine Premiere, 230, 82-85.

Zurian, Francisco (2011). «Almodóvar, la identidad de género buscada: El caso de La piel que habito». En: Zurian, Francisco (ed.). Imágenes del Eros: Género, sexualidad, estética y cultura audiovisual. Madrid: Ocho y Medio, 277-297.

\section{Filmografía}

The Hunger Games (Los juegos del hambre). Dir. Gary Ross, 2012.

The Hunger Games: Catching Fire (Los juegos del hambre: En llamas). Dir. Francis Lawrence, 2013.

The Twilight Saga: New Moon (La saga Crepúsculo: Luna nueva). Dir. Chris Weitz, 2009. 